\title{
An Empirical Analysis of Technology Transfer of National R\&D Projects in South Korea
}

\author{
Mi-Sun Kim, ${ }^{1}$ Dong-Ho Shin, ${ }^{1}$ Jae-Soo Kim, ${ }^{2}$ and Byeong-Hee Lee ${ }^{2}$ \\ ${ }^{1}$ Korea University of Science and Technology (UST), 217 Gajeong-ro, Yuseong-gu, Daejeon 305-350, Republic of Korea \\ ${ }^{2}$ Korea Institute of Science and Technology Information (KISTI), 245 Daehak-ro, Yuseong-gu, Daejeon 305-806, Republic of Korea \\ Correspondence should be addressed to Byeong-Hee Lee; bhlee@kisti.re.kr
}

Received 28 August 2014; Accepted 27 October 2014

Academic Editor: Seungmin Rho

Copyright (c) 2015 Mi-Sun Kim et al. This is an open access article distributed under the Creative Commons Attribution License, which permits unrestricted use, distribution, and reproduction in any medium, provided the original work is properly cited.

\begin{abstract}
This study is aimed at seeking policy implications for the policy makers of South Korean government and finding a direction to support R\&D institutions in performing R\&D activities more efficiently, by analyzing the factors influencing technology transfer of the national R\&D projects. The data retrieved from NTIS (National Science \& Technology Information Service) was used in analyzing the results of 575 projects with 1,903 cases of technology transfer, performed by the Ministry of Science, ICT and Future Planning, between 2002 and 2012. We found that there were significant differences between the government funded institutions and the universities and between basic R\&D and applied ones. We also discovered that the government funded institutions did not necessarily take a better position than the universities in terms of the quantity of technology transfer. Lastly, the applied R\&D of the universities was very vulnerable in terms of technology transfer.
\end{abstract}

\section{Introduction}

The interest in the technology transfer has increased, as the R\&D scopes have been wider and the territories among the industries have been loosened. Technology transfer is defined as the flow of the technology from an entity to another one $[1,2]$, and it is also defined as the transfer of the physical assets, know-how, and the technical knowledge [3]. Other definitions look at technology transfer as a proactive process, in which the obtained knowledge, experiences, or the outcomes are diffused into the society [4]. In addition, Mittelman and Pasha [5] explained the technology transfer as the flow from the creation of knowledge, skills, organizations, values, or capital to their stabilized applications through its introduction. To facilitate the flow of technology, several countries set up a legal framework. With regards to technology transfer related laws, Stevenson-Wydler's Technology Innovation Act in 1980 and Federal Technology Transfer Act in 1986, in America, set up the framework to connect the producers of the knowledge and its users. The regulations allowed setting CUFT, The Center for the Utilization of Federal Technology, inside NTIS (National Technical Information Service) to facilitate efficient technology transfer and have enforced that at least more than $0.5 \%$ of the R\&D budget has to be spent on technology transfer. They set technology transfer as one of the important government duties and have strived to facilitate it by reflecting it in the evaluation of the government [6]. In the case of Korea, a movement to increase efforts in facilitating the technology transfer was initiated in 2000, along with the technology transfer promotion act. Many studies were conducted to encourage technology transfer: however, the most of these studies have only focused on the system and were not able to boost technology transfer, although the related infrastructures were built up, thanks to them [7]. In order to resolve this problem, in 2014, Korean government announced to invest approximately 9 hundred billion KRW (approx. 900 million USD) to provide support for technology transfer by 2017 , which meant increasing up to $4.0 \%$ of the total R\&D investment amount [8]. The purposes of this budget increase are to facilitate the circulation of research outcomes and to strengthen the relationship between research and its applications. The values of the R\&D projects depend on creating and utilizing R\&D outcomes, through which national $\mathrm{R} \& \mathrm{D}$ projects aimed to aid the national development [9]. Although science and technology is often not able to produce outcomes quickly, the failure in $R \& D$ should be 
accepted as necessary, and there would be various ways to utilize the results. However, the final goal of $\mathrm{R} \& \mathrm{D}$ should be to make a contribution to national development through creating and utilizing the fruits of the successful R\&D.

In 2014, we should now contemplate on the utilization of the technologies, as Korea has heavily invested on science and technology, which almost has the highest investment rate on R\&D against GDP [10], and has been able to achieve high growth rate in a short period, thanks to science and technology. Therefore, this study was aimed at empirically analyzing the results of the technology transfer of national $\mathrm{R} \& \mathrm{D}$ projects in Korea. We believe that the outcomes of this study would be useful in drawing attention to policy implications for the policies to efficiently support and manage the creation and utilization of the R\&D outcomes. We will review the technology transfer of national R\&D projects, supported by Korean government, by the types of R\&D organizations, and by the types of R\&D. Then, we will propose the policy implications in which the national R\&D supporting policies are efficiently applied, respectively, by the types of R\&D organizations and by the types of R\&D. We will also review how the lead-time from the completion of R\&D to the technology transfer affects the royalties, the benefits of the technology. Lastly, we propose the direction of the policies for the technology transfer by tracing the results of national R\&D projects with the same purpose to diffuse $\mathrm{R} \& \mathrm{D}$ outcomes.

\section{Concepts and Global Trends}

There is a growing trend in the investment amounts in $R \& D$ all over the world. The investment in $\mathrm{R} \& \mathrm{D}$ is increasing not only in industrial sector but also in national R\&D projects. Figure 1 shows the gross domestic expenditure on R\&D (GERD) of several major countries in the world. Approximately $41 \%$ of the total GERD in OECD countries was spent by America, and main 7 countries, that is, America, Japan, Germany, Korea, France, UK, and Italy, invested about $80 \%$ of the GERD of the total 34 OECD countries, in R\&D. Among non-OECD countries, China, Russia, and Taiwan were also shown to heavily invest in $\mathrm{R} \& \mathrm{D}$, almost at a comparable level with that in the above 7 countries.

Figure 2 shows GERD against the economic scales of each country. It presents the $R \& D$ investment amount against GDP, based on the data given by OECD in July 2014. When the average of OECD was taken as " 1 ," Korea invested 1.8 times more than the average of OECD and comparatively small countries, such as Israel, Finland, Sweden, and Korea, showed high percentages of $\mathrm{R} \& \mathrm{D}$ investment against their GDPs.

Then, do they make enough direct gains from the technologies or indirect ones by creating, such as a new technology market by utilizing them, as they heavily invested on $\mathrm{R} \& \mathrm{D}$ ? According to the report of the Korean Ministry of Commerce, Industry and Energy, Korea has only a half of the technology transfer, compared to the main technologically advanced countries, America or European ones [7]. It could be explained by closed culture of Korea in which people do not take advantage of existent technologies for their research. Also we suspect the lack of efficient tracking system on national $\mathrm{R} \& \mathrm{D}$ projects and excessive administrative work that

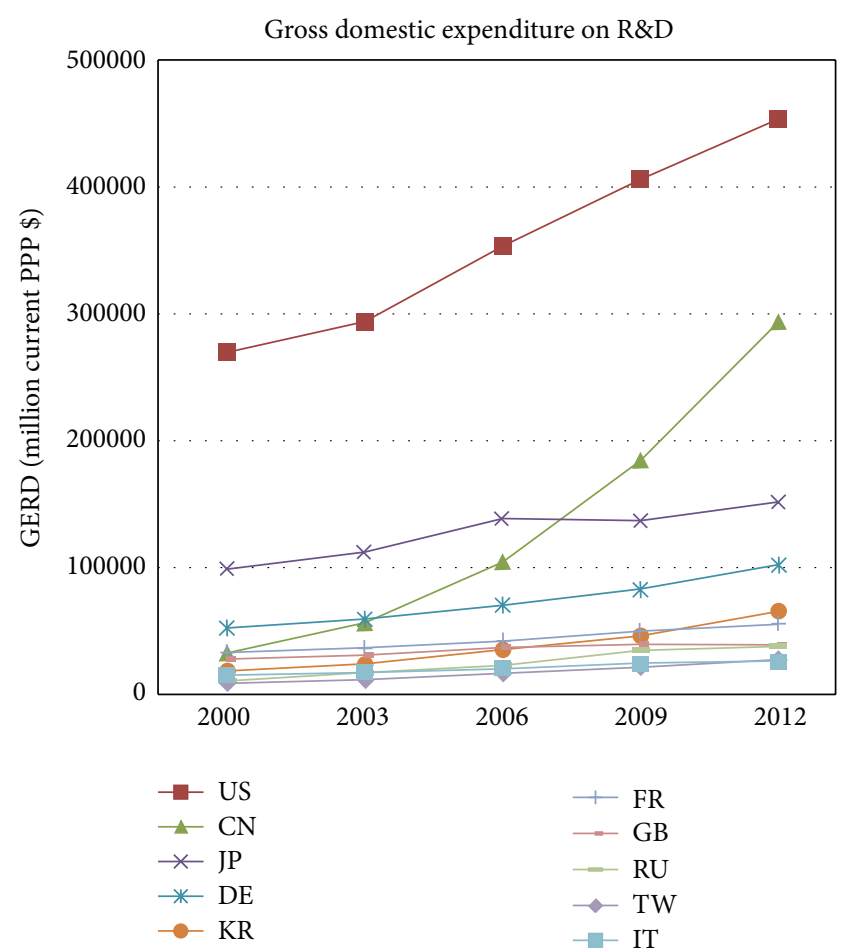

FIgURE 1: Gross domestic expenditure on the R\&Ds (reedition of OECD's data in 2014).

may lead to weak outcomes and become a hindrance for efficient research. There are several reasons why technology transfer is difficult to achieve; these include the following: (1) there are differences between the universities and the industries in R\&D methods and (2) there are again discrepancies between them in terms of the R\&D goals or objectives [11]. In addition, national R\&D projects in Korea have continuously increased in number and in size, except for the types of supporting organizations. They increased from 108 in 1998 to 408 in 2012, and the related budget also rose sharply from 1,942,500,000,000 won (billion and 950 million USD) in 1998 to $10,744,500,000,000$ won (10 billion and 750 million USD) in 2012 [12]. We need to pay attention to the efficiency of the investments and the structure of the projects, as the scales of the national $\mathrm{R} \& \mathrm{D}$ projects are bigger. With regards to the above mentioned trend, Kwon et al. [13] analyzed the factors influencing the 21th century frontier $R \& D$ project, one of the national $R \& D$ projects. Whether the types of the $R \& D$ organizations, the types of $R \& D$, the lead-time of $R \& D$, or the field of the R\&D projects showed the differences in the outcomes was analyzed and it was found that the universities had the high research paper outcomes, the industries had the high rate of patent applications and registrations, and the long-term researches with 6 years and more had the high rate of patent applications. However, Kwon et al. [13] had a limitation in that it counted only the technology transfer related contracts, which failed to consider the qualitative outcomes of the technology transfers. So far, the studies on the project unit have been frequently conducted. However, this study will review the relation between the types of 


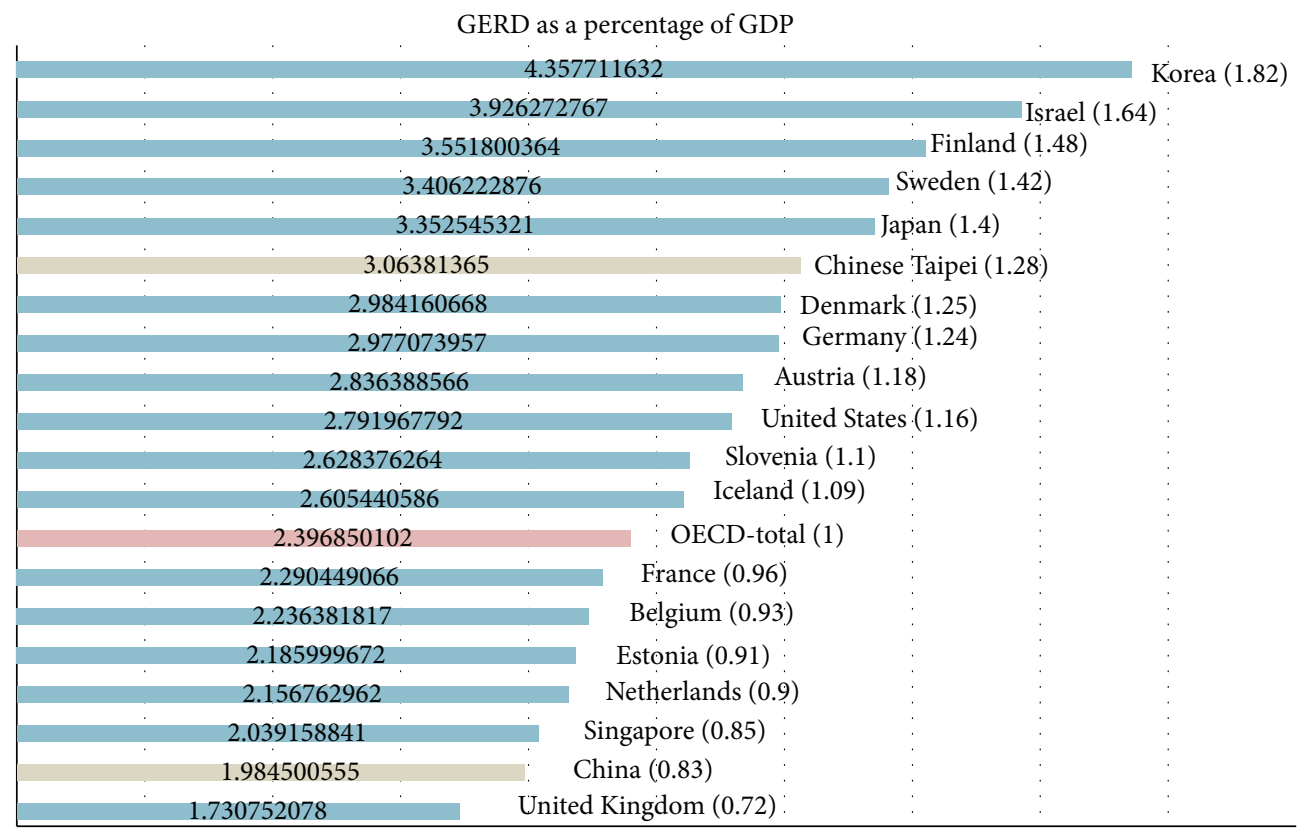

FIGURE 2: The proportion of GERD against GDP.

the $R \& D$ organizations, the types of $R \& D$ and the lead-time from the completion of R\&D to technology transfer, and the transfer, with the overall outcomes of the national R\&D projects by the Ministry of Science and Technology in Korea [14].

\section{Hypotheses}

The study sets up hypotheses as shown below to analyze the factors influencing the technology transfer of the national $\mathrm{R} \& \mathrm{D}$ projects in Korea.

Hypothesis (1): There Is a Significant Difference in Technology Transfer by the Types of the R\&D Organizations. Depending on who conducts $\mathrm{R} \& \mathrm{D}$, that is, the universities, the government-funded research institutes, or the industries, the purposes of the activities and the characteristics of the participants are different. When applying the same criteria to the all $\mathrm{R} \& \mathrm{D}$ organizations, having different $\mathrm{R} \& \mathrm{D}$ directions and purposes, it is equivalent to a molding with an already fixed frame regardless of differences. In the study by Cohen et al., he emphasized on the fact that there was a clear difference between the universities' innovation and that of the industries [15-18]. In this regard, Rosenberg and Nelson [11] addressed that the difficulty in bringing the $\mathrm{R} \& \mathrm{D}$ outcomes to the market was the difference in R\&D between universities and industries, and the transfer of the outcomes between them was difficult to achieve, as their R\&D activities had different focuses and goals. In addition, when [13] analyzed the outcomes of the 21th century frontier R\&D project, one of the national $\mathrm{R} \& \mathrm{D}$ projects, he addressed that the universities had the high research paper outcomes and the industries had the high rate of patent applications and registrations and interpreted the analysis results were due to the fact that
TABLE 1: The R\&D development stages.

\begin{tabular}{ll}
\hline $\begin{array}{l}\text { R\&D development } \\
\text { stage }\end{array}$ & Criteria \\
\hline Basic R\&D & $\begin{array}{l}\text { Originally conducted, a theoretical or } \\
\text { experimental R\&D to obtain a new } \\
\text { knowledge on the observable objects or the } \\
\text { natural phenomena, without any purpose of } \\
\text { a special application or industrialization }\end{array}$ \\
\hline Applied R\&D & $\begin{array}{l}\text { An R\&D initiative to obtain new scientific } \\
\text { knowledge mainly with a practical purpose } \\
\text { or goal, utilizing the knowledge given by } \\
\text { basic R\&D }\end{array}$ \\
\hline Development R\&D & $\begin{array}{l}\text { A systematic research to substantially } \\
\text { improve the products, which are already } \\
\text { product or equipment by utilizing the } \\
\text { knowledge obtained from basic, applied } \\
\text { R\&D or actual experience }\end{array}$ \\
\hline Others & $\begin{array}{l}\text { Other R\&D activities, which do not belong } \\
\text { to any of the above categories }\end{array}$ \\
\hline
\end{tabular}

the universities and the industries had the different viewpoints from each other in their R\&D activities.

Hypothesis (2): According to the Types of R\&D, There is a Significant Difference in the Outcomes of Technology Transfer. OECD divides R\&D types into the basic, the applied, and the development types [19]. NTIS in Korea also collects the related basic, applied, development, and other research data, in accordance with the criteria of OECD, shown in Table 1.

Grimaldi and von Tunzelmann [20] proved that the applied R\&D had clear success factors, compared to the basic R\&D, by analyzing LINK program, which was a big scaled 

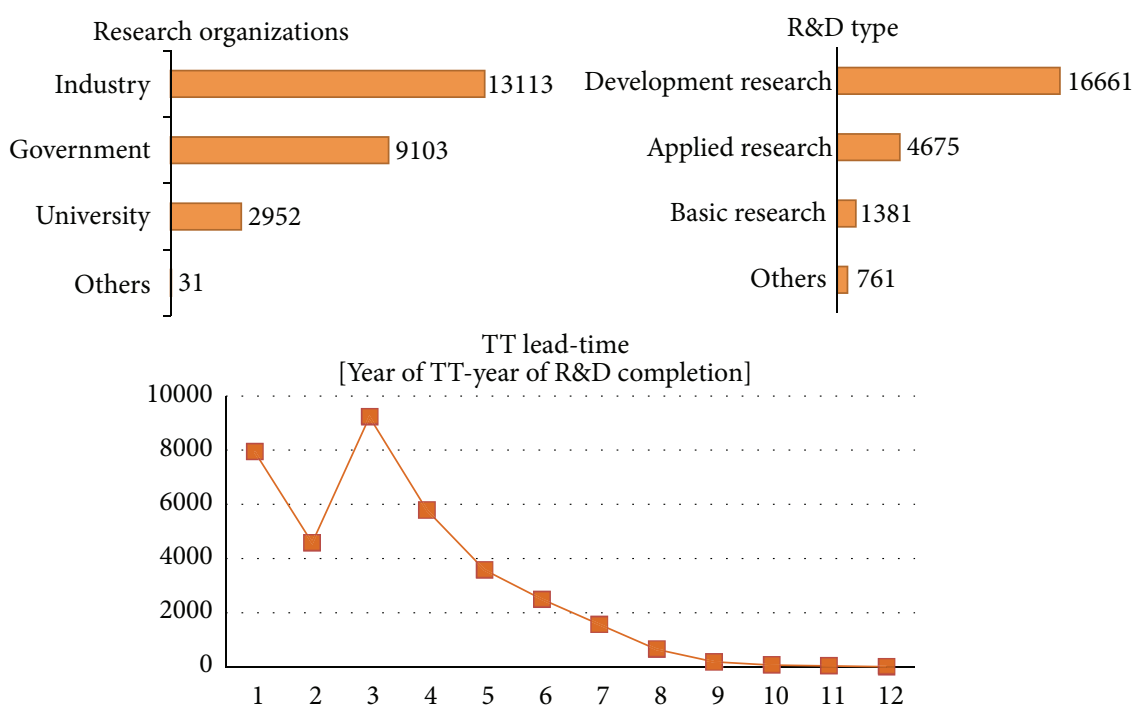

FIGURE 3: The outcomes of the technology transfer (TT) of the overall national R\&D projects.

R\&D project in UK. Although the study was only limited to the big scaled $R \& D$ project, we believe that it will be applicable in the overall technologies, and according to the characteristics of the each R\&D type, the outcomes of R\&D may be different. Therefore, it is applicable in analyzing the differences in the technology transfer by the types of R\&D.

Hypothesis (3): According to the Lead-Time from the Completion of R\&D to Technology Transfer, There is a Significant Difference in the Outcomes of the Transfer. From the study result that the long-term R\&D had more domestic patent applications than the short-term R\&D [12], the above hypothesis is set up to analyze the influence of the lead-time from the completion of R\&D to the technology transfer. Also this hypothesis aimed to look at data pattern related to the time elapsed between the research and the utilization of the technology. The lead-time is defined from the starting year of the research to the year of the transferred technology. Consequently this study could give stakeholders a basis for a suitable policy to evaluate the project period and the expected outcomes.

\section{Research Methodology and Data}

4.1. Basic Statistics Data. This study utilized the data of NTIS (National Science \& Technology Information Service), which collected the information and data, including the goals, the participants, the facilities, and the outcomes, of the national R\&D projects run by 17 ministries and administration (16 representative specialists) of South Korea, and data analysis was performed with $\mathrm{R}$ package. The data was collected from 2002 as the starting year of the projects and from 2006 as transferred year, on the basis of 23,478 cases opened to the public by 2012. From the analysis of the data, we found that small or medium sized businesses which is industry in Figure 3 dominated in the technology transfer covering about $51 \%$ of the total transfer and the development research transfer covered $71 \%$ of the total transfer, as shown in
Figure 3, TT refer to technology transfer. We decided to only focus on the technology transfer done by the Ministry of Technology, ICT and Future Planning, the technology related government organization, to avoid the study biasing towards the outcomes produced by the small or medium sized businesses.

Figure 4 shows the technology transfer done by the Ministry of Technology, ICT and Future Planning, on the basis of analyzing 575 projects with 1,903 cases of technology transfer from 2002 to 2012. The transfer by the ministry through their projects was $56.38 \%$ to the universities, $40.25 \%$ to the government-funded research institutes, and $2.9 \%$ to the industries and mainly concentrated on applied R\&D. In cases of the industries, mostly the transfer was done from the projects by small and medium business administration to small or medium sized businesses, and it was unique that the transfer was approximately $73 \%$ in the same years of the projects.

4.2. Variables and the Summary of the Statistics. In analyzing the outcomes of the technology transfer of the national R\&D projects, this study sets the number of the transfer and the royalties with the transfer as the dependent variables of $R \& D$ outcomes and sets the types of $R \& D$ organizations, the $R \& D$ types, and the lead-time of the technology transfer as the independent variables. The details of the variables in this study are shown in Table 2.

In Table 2, the lead-time from the completion of $R \& D$ to the technology transfer was calculated by deducing from the year of the technology transfer to the completion year of R\&D. The summary statistics on each variant is shown in Table 3; in the types of $R \& D$ organizations, $G$ refers to the government, I to the industries, and $\mathrm{U}$ to the universities; in the $\mathrm{R} \& \mathrm{D}$ types, $\mathrm{B}$ refers to basic $\mathrm{R} \& \mathrm{D}$, A to applied $\mathrm{R} \& \mathrm{D}$, and $\mathrm{D}$ to development $\mathrm{R} \& \mathrm{D}$, and Time means the lead-time from the completion year of $\mathrm{R} \& \mathrm{D}$ to the year of technology transfer. The coefficient variables $(\mathrm{CV})$ show that 


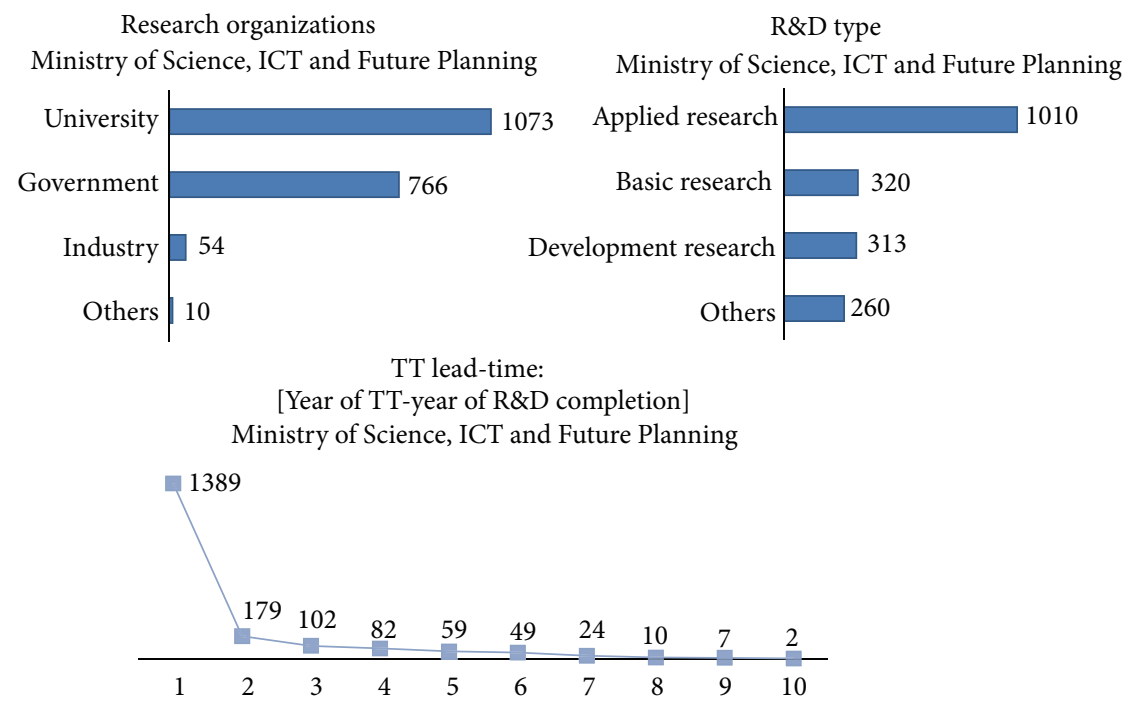

FIGURE 4: The outcomes of the technology transfer by the science and technology related ministry of the national R\&D projects.

TABLE 2: The categories of the variables and the details.

\begin{tabular}{|c|c|c|}
\hline \multirow{3}{*}{ Independent variable } & Type of research organization (a) & $\begin{array}{l}\text { Government-funded research institutes } \\
\text { (1), industry (2), and universities (3) }\end{array}$ \\
\hline & R\&D type (b) & $\begin{array}{l}\text { Basic research (1), applied research (2), } \\
\text { and development research (3) }\end{array}$ \\
\hline & $\begin{array}{l}\text { Lead-time from the completion of R\&D } \\
\text { to technology transfer (c) }\end{array}$ & 0 years to 8 years \\
\hline \multirow{2}{*}{ Dependent variable } & Number of technology transfer cases (A) & $\begin{array}{l}\text { The contracts for the technology transfers } \\
\text { during the above mentioned period }\end{array}$ \\
\hline & Royalties (B) & $\begin{array}{l}\text { The technology transfer related royalties, } \\
\text { set with sections }\end{array}$ \\
\hline
\end{tabular}

the variation of each independent variable is getting bigger with the number of the transfer than with the royalties.

4.3. The Analysis Methodology. This study was aimed at finding a direction to improve the policies related technology transfer and facilitating efficient R\&D activities and transfer, by analyzing the outcomes of the transfer of the national $R \& D$ projects, by the types of $R \& D$ organizations, by the $\mathrm{R} \& \mathrm{D}$ types, and by the lead-time of the technology transfer. The normality should be verified to analyze the influences of the types of the R\&D organizations, that is, the governmentfunded research institutes, the industries, and the universities on the number of the technology transfer (TT) and the royalties. As the normality was not valid, Kruskal-Wallis test, as nonparametric one, was applied for the further analysis. It was the same for the analysis of the R\&D types. If a significant difference was found through Kruskal-Wallis test, the data was analyzed with Kruskalmc to find which independent variable particularly influenced the specific dependent ones [21]. The lead-time from the completion of R\&D and to the technology transfer was analyzed with regression analysis, as the lead-time was continuous.

\section{The Analysis Results}

The study results validated the above addressed 3 hypotheses. In Section 5.1, the 1st hypothesis, which was about the case if the types of the $\mathrm{R} \& \mathrm{D}$ organizations brought a significant difference in the outcomes of technology transfer, and the 2nd hypothesis, which was about the case if the types of R\&D caused a significant difference in the outcomes of the transfer, were tested with 5\% significance level. In Section 5.2, the 3 rd hypothesis, which was about the case if the lead-time of the technology transfer had a significant difference, was reviewed.

5.1. The Analysis of the Outcomes by the Types of ReD Organizations and the Types of R\&D. The results of the normality test with 5\% significance level are shown in Table 4. Table 5 shows Kruskal-Wallis test results and the test was applied, as there was no normality in all conditions, that is, between A-a, A-b, B-a, and B-b.

As shown in Table 5, the number of the technology transfer (TT) (A) shows a significant difference with the types of the organizations (a) and the types of R\&D (b) in Kruskal-Wallis test. However, royalties (B) does not show a 
TABLE 3: The summary of basic statistics.

(a)

\begin{tabular}{lccccc}
\hline $\begin{array}{l}\text { Dependent } \\
\text { variable }\end{array}$ & Type of organization & $N$ & Mean & S.D. & CV \\
\hline $\begin{array}{l}\text { Number of } \\
\text { TT }\end{array}$ & G(a1) & 301 & 1.3986 & 1.324 & 0.9467 \\
(A) & $\mathrm{I}(\mathrm{a} 2)$ & 37 & 1.2162 & 0.479 & 0.3938 \\
& $\mathrm{U}(\mathrm{a} 3)$ & 237 & 2.194 & 2.932 & 1.3364 \\
\hline
\end{tabular}

(b)

\begin{tabular}{lccccc}
\hline $\begin{array}{l}\text { Dependent } \\
\text { variable }\end{array}$ & Type of organization & $N$ & Mean & S.D. & CV \\
\hline \multirow{3}{*}{ Royalties (B) } & $\mathrm{G}(\mathrm{a} 1)$ & 301 & 7.847 & 5.844 & 0.7447 \\
& $\mathrm{I}(\mathrm{a} 2)$ & 37 & 10.000 & 6.868 & 0.6868 \\
& $\mathrm{U}(\mathrm{a} 3)$ & 237 & 8.068 & 6.028 & 0.7471 \\
\hline
\end{tabular}

(c)

\begin{tabular}{lccccc}
\hline $\begin{array}{l}\text { Dependent } \\
\text { variable }\end{array}$ & R\&D type & $N$ & Mean & S.D. & CV \\
\hline Number of & B(b1) & 159 & 2.235 & 2.954 & 1.3217 \\
TT & $\mathrm{A}(\mathrm{b} 2)$ & 264 & 1.189 & 0.597 & 0.5021 \\
$(\mathrm{~A})$ & $\mathrm{D}(\mathrm{b} 3)$ & 152 & 1.362 & 1.064 & 0.7812 \\
\hline
\end{tabular}

(d)

\begin{tabular}{lccccc}
\hline $\begin{array}{l}\text { Dependent } \\
\text { variable }\end{array}$ & R\&D type & $N$ & Mean & S.D. & CV \\
\hline \multirow{3}{*}{ Royalties (B) } & B(b1) & 159 & 8.458 & 5.941 & 0.7024 \\
& A(b2) & 264 & 7.057 & 5.842 & 0.8278 \\
& D(b3) & 152 & 8.480 & 6.165 & 0.7270 \\
\hline
\end{tabular}

(e)

\begin{tabular}{lccccc}
\hline $\begin{array}{l}\text { Dependent } \\
\text { variable }\end{array}$ & Taken time & $N$ & Mean & S.D. & CV \\
\hline Royalty (B) & Time (c) & 575 & 1.318 & 1.864 & 1.4143 \\
\hline
\end{tabular}

TABLE 4: Normality test.

\begin{tabular}{lcc}
\hline $\begin{array}{l}\text { Dependent } \\
\text { variable }\end{array}$ & $\begin{array}{c}\text { Independent } \\
\text { variable }\end{array}$ & Result \\
\hline $\begin{array}{l}\text { Number of } \\
\text { TT (A) }\end{array}$ & $\begin{array}{c}\text { Organization } \\
\text { (a) }\end{array}$ & $P$ value $<2.2 e-16$ \\
\hline & R\&D type (b) & $P$ value $<2.2 e-16$ \\
Royalties (B) & $\begin{array}{c}\text { Organization } \\
\text { (a) }\end{array}$ & $P$ value $=5.041 e-16$ \\
& R\&D type (b) & $P$ value $=1.669 e-15$ \\
\hline
\end{tabular}

significant difference with $5 \%$ significance level with the types of the organizations (a), and types of R\&D (b) is close to the significant level $\alpha=0.05$, which means that it is just statistically significant.

The results of postmortem analysis of Kruskalmc, to compare which type of the organizations shows the difference with the technology transfer, are shown in Table 6 . The table also shows the multiple analysis results on the relation between the 3 different types of the organizations and the technology transfer and the royalties. First, the 1st hypothesis, which was about the case if the types of the $\mathrm{R} \& \mathrm{D}$ organizations, that is, the government-funded research institutes, the industries, and the universities, brought a significant difference in the outcomes of the technology transfer, was partially proved. The reason why it was only partially proved is that the significant difference was only shown with the number of the transfer but not with the royalties. Particularly, the number of the transfer clearly shows the significant outcomes between the universities and the government-funded research institutes, while it does not show any significant outcomes between the governmentfunded research institutes and the industries or the universities and the industries. The industries belong to the 2 results without statistical significances; it can be interpreted as they conduct the related R\&D activities from the initial stages, according to their own purposes, and therefore, they have very strong purposes to utilize the technologies by themselves rather than transfer, which is obviously different from the universities and the government-funded research institutes. Second, the 2nd hypothesis, where the types of $\mathrm{R} \& \mathrm{D}$, that is, the basic, the applied, and the development R\&D, brought a significant difference in the outcomes of the transfer, was proved. Particularly, the observed values between the basic $R \& D$ and the applied $R \& D$ and the number of the technology transfer and the royalties were greater than the verification threshold, which were all statistically significant. However, the development research group was not significantly different from the basic research group and the applied research one.

Through the above analysis, this study found that there were significant differences between the number of the technology transfer and the universities and the governmentfunded research institutes and between the number of the transfer and the basic R\&D and the applied R\&D. Therefore, 4 groups, that is, the government-funded basic $R \& D$, the government-funded applied $R \& D$, the universities with the basic $R \& D$, and the universities with the applied $R \& D$, were compared through multiple comparison analysis and the following are the results. The results of analysis are shown in Table 7.

If the types of R\&D were additionally considered with the types of the R\&D organizations, (1) government-funded basic R\&D had the higher numbers of the transfer than the universities with the applied R\&D. However, the result could not be considered significant when it was compared with that of the universities regarding basic R\&D. (2) Governmentfunded applied R\&D showed the higher numbers in the transfer than the one of the universities with the applied R\&D. However, again it could not be considered as significant when it was compared with the one of the universities with the basic R\&D.

5.2. The Analysis of the Outcomes by the Lead-Time of the Technology Transfer and the Types of ReD. The results of the analysis on the lead-time of the technical transfer applied regression analysis are shown in Table 8 . The 3rd hypothesis is accepted as royalties according to the fact that the leadtime was statistically significant. However, the persuasiveness was very weak with $1 \%$, as it was difficult to generalize 
TABLE 5: Kruskal-Wallis test.

\begin{tabular}{lccc}
\hline Dependent variable & Independent variable & Result \\
\hline \multirow{2}{*}{ Number of TT (A) } & Organization (a) & $X^{2}=19.3439, \mathrm{df}=2$ & $P$ value $=6.303 e-05^{* * *}$ \\
& R\&D type (b) & $X^{2}=25.885, \mathrm{df}=2$ & $P$ value $=2.394 e-06^{* * *}$ \\
\hline \multirow{2}{*}{ Royalties (B) } & Organization (a) & $X^{2}=3.4139, \mathrm{df}=2$ & $P$ value $=0.1814$ \\
& R\&D type (b) & $X^{2}=6.9971, \mathrm{df}=2$ & $P$ value $=0.03024^{*}$ \\
\hline
\end{tabular}

Signif. codes: ${ }^{* * *} P<0.001,{ }^{* *} P<0.01$, and ${ }^{*} P<0.05$.

TABLE 6: Multiple comparison.

\begin{tabular}{|c|c|c|c|c|c|c|}
\hline Dependent variable & Indepe & riable & & Obs. dif. & Critical dif. & Difference \\
\hline \multirow{6}{*}{ Number of TT (A) } & \multirow{3}{*}{ Organization (a) } & G & I & 0.97543 & 69.28660 & False \\
\hline & & G & $\mathrm{U}$ & 46.01721 & 34.53892 & True \\
\hline & & I & $\mathrm{U}$ & 45.04138 & 70.30323 & False \\
\hline & \multirow{3}{*}{ R\&D type (b) } & B & A & 60.56925 & 39.92498 & True \\
\hline & & B & $\mathrm{D}$ & 21.71808 & 45.11644 & False \\
\hline & & A & $\mathrm{D}$ & 38.85118 & 40.49468 & False \\
\hline \multirow{3}{*}{ Royalties (B) } & \multirow{3}{*}{ R\&D type (b) } & B & A & 41.63243 & 39.92498 & True \\
\hline & & B & $\mathrm{D}$ & 39.42918 & 45.11644 & False \\
\hline & & $\mathrm{A}$ & $\mathrm{D}$ & 2.20325 & 40.49468 & False \\
\hline
\end{tabular}

TABLE 7: Multiple comparisons considering the types of R\&D.

\begin{tabular}{llcccc}
\hline Dependent variable & \multicolumn{2}{c}{ Independent variable } & Obs. dif. & Critical dif. & Difference \\
\hline & GB & UA & 103.35820 & 78.13171 & True \\
Number of TT (A) & GB & UB & 7.91700 & 85.77833 & False \\
& GA & UB & 20.39063 & 75.24104 & False \\
& GA & UA & 75.05057 & 66.39168 & True \\
\hline
\end{tabular}

TABLE 8: Simple linear regression test.

\begin{tabular}{lccccrrr}
\hline Dependent variable & Independent variable & $y$-Intercept & Gradient & $R^{2}$ & $\mathrm{Ra}^{2}$ & $F(\mathrm{df})$ & $P$ value \\
\hline Royalties (B) & Lead-time (c) & 7.6086 & 0.3549 & 0.01217 & 0.01045 & 7.061 & $0.0081^{* *}$ \\
\hline Signif. codes: ${ }^{* * *} P<0.001,{ }^{* *} P<0.01$, and ${ }^{*} P<0.05$ & & & & &
\end{tabular}

it with the weak persuasiveness. The results signified that responding to the flow of the markets and the technologies with flexibility, rather than forecasting the lead-time of the technology transfer in advance before starting R\&D, would increase the efficiency of the transfer in both quantity and quality. However, it will be worth comparing it with the results with the bigger parameter. The study significantly showed that long-term projects brought positive economical results rather than an adventure in the end. At the same time, the study showed that too much speculated technologies and $\mathrm{R} \& \mathrm{D}$ periods would not be necessarily positive in generating revenue.

\section{Conclusion}

The study reviewed the outcomes of national $R \& D$ projects by the types of R\&D organizations and by the types of R\&D and analyzed the factors influencing the outcomes. The purpose of the study was to propose the direction of the policies for the technology transfer by tracing the results of the national $\mathrm{R} \& \mathrm{D}$ projects with the same purpose. Therefore, this study analyzed how the outcomes of the technology transfer influenced the number of the transfer and the royalties, by the types of R\&D organizations and by the types of $R \& D$, and what the relation between the lead-time from the completion of $\mathrm{R} \& \mathrm{D}$ to the technology transfer and the royalties was. As the analysis result, we found there were significant differences between the government-funded R\&D institutions and the universities and the basic R\&D and the applied R\&D. The 4 groups, that is, the government-funded basic $\mathrm{R} \& \mathrm{D}$, the government-funded applied $R \& D$, the universities with the basic $R \& D$, and the universities with the applied $R \& D$, were compared through multiple comparison analysis. The results of the analysis showed that the government-funded basic R\&D had the higher numbers of the transfer than the universities with the applied R\&D. However, the result could not be considered significant, when it was compared with the one of the universities with the basic R\&D. The governmentfunded applied R\&D showed the higher numbers in the transfer than the one of the universities with the applied R\&D. However, again it could not be considered significant when it was compared with the one of the universities with the basic 
R\&D. It signified that the government-funded institutions and the universities had the open possibility of the technology transfer as they had relatively the character of public interest or influence. They showed statistically significant difference in royalties. However, the persuasiveness was very weak which implied that they considered the technology transfer as the public assets rather than their own economic benefits. On the other hand, it was interpreted as their R\&D purposes were about the technology transfer itself, rather than generating the economic values through the transfer. The analysis result of the types of R\&D organizations with the consideration of the types of $R \& D$ showed that the government-funded $R \& D$ institutions may not always have a better position over the universities in terms of quantity of the technology transfer and also demonstrated that the universities with the applied $\mathrm{R} \& \mathrm{D}$ projects were very weak in terms of technology transfer. Further study is required to check a trigger to facilitate the technology transfer by the universities with the applied R\&D and also validate the qualitative relation with R\&D budget. With regard to the qualitative relation, Ok and Kim [22] analyzed that R\&D budgets clearly influenced the number of the technology transfer, the royalties, and the number of the new technologies, and the individual R\&D capacity (the number of the SCI articles per head) was also statistically significant in raising the efficiency of the transfer of the universities. Although the study was about the outcomes of the universities, it would be also very interesting if it is compared with the economic values with input and output on the national $\mathrm{R} \& \mathrm{D}$ projects.

\section{Conflict of Interests}

The authors declare that there is no conflict of interests regarding the publication of this paper.

\section{Acknowledgments}

This research was supported by the Sharing and Diffusion of National R\&D Outcome funded by the Korea Institute of Science and Technology Information.

\section{References}

[1] W. E. Souder, A. S. Nashar, and V. Padmanabhan, "A guide to the best technology-transfer practices," The Journal of Technology Transfer, vol. 15, no. 1-2, pp. 5-16, 1990.

[2] K. Ramanathan, "The polytrophic components of manufacturing technology," Technological Forecasting and Social Change, vol. 46, no. 3, pp. 221-258, 1994.

[3] B. Bozeman, "Technology transfer and public policy: a review of research and theory," Research Policy, vol. 29, no. 4-5, pp. 627$655,2000$.

[4] A. P. Hameri, "Technology transfer between basic research and industry," Technovation, vol. 16, pp. 51-57, 1996.

[5] J. H. Mittelman and M. K. Pasha, Out from Underdevelopment Revisited: Changing Global Structures and the Remaking of the Third World, St. Martins Press, New York, NY, USA, 1997.

[6] R. C. Dorf and K. K. F. Worthington, "Models for commercialization of technology from universities and research laboratories," The Journal of Technology Transfer, vol. 12, no. 1, pp. 1-8, 1987.

[7] C. Y. Lim and Y. J. Lee, An Analysis for Success Factor of Technology Transfer: From GRI's Perspectives, STEPI, 2007.

[8] The Ministry of Science, ICT, and Future Planning of Republic of Korea, "The technical commercialization promotion planning for R\&D result diffusion," 2014.

[9] D. B. Chung and D. D. Jung, "The effects of performance management \& application capabilities and activities on technology transfer from Public Research Institutes in Korea," Journal of Technology Innovation, vol. 21, pp. 199-223, 2013.

[10] OECD, July 2014, http://www.oecd.org/statistics/.

[11] N. Rosenberg and R. R. Nelson, "American universities and technical advance in industry," Research Policy, vol. 23, no. 3, pp. 323-348, 1994.

[12] Y. S. Ko, "The analysis of the process of the structural change in national R\&D projects," The Survey Report, KISTEP, 2014.

[13] J. C. Kwon, J. B. Moon, Y. J. Yoo, and C. G. Lee, "Achievement characteristic analysis for large scale government R\&D projects focusing on 21st century frontier R\&D program," Journal of Korea Technology Innovation Society, vol. 15, pp. 185-202, 2012.

[14] M. S. Kim, D. H. Shin, J. S. Kim, and B. H. Lee, "Performance analysis on technology transfer in national R\&D project," in Proceedings of the International Conference of on Convergence Content (ICCC '14), vol. 12, pp. 5-6, June 2014.

[15] W. M. Cohen, A. Goto, A. Nagata, R. R. Nelson, and J. P. Walsh, "R\&D spillovers, patents and the incentives to innovate in Japan and the United States," Research Policy, vol. 31, no. 8-9, pp. 13491367, 2002.

[16] R. C. Levin, A. K. Klevorick, R. R. Nelson, and S. G. Winter, "Appropriating the returns from industrial research and development," Brookings Papers on Economic Activity, vol. 1987, pp. 783-831, 1987.

[17] E. Mansfield, "Academic research and industrial innovation," Research Policy, vol. 20, no. 1, pp. 1-12, 1991.

[18] D. C. Mowery and B. N. Sampat, "The Bayh-Dole Act of 1980 and university-industry technology transfer," Journal of Technology Transfer, vol. 30, no. 1-2, pp. 115-127, 2004.

[19] OECD, "Frascati Manual," 2002.

[20] R. Grimaldi and N. von Tunzelmann, "Sectoral determinants of performance in collaborative $\mathrm{R} \& \mathrm{D}$ projects," International Journal of Technology Management, vol. 25, no. 8, pp. 766-778, 2003.

[21] S. Siegel and N. J. Castellan, Nonparametric Statistics for the Behavioral Sciences, McGraw-Hill, 1988.

[22] J. Y. Ok and B. K. Kim, "Measuring the performance of technology transfer activities of the public research institutes in Korea," Journal of Technology Innovation, vol. 17, pp. 131-158, 2009. 

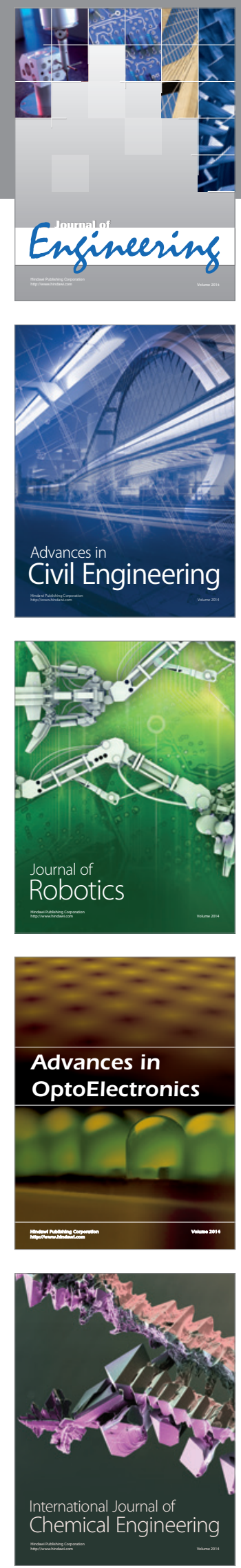

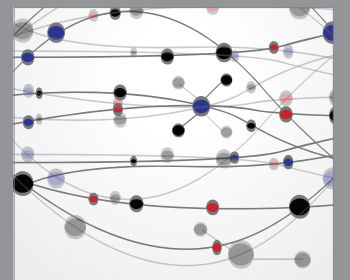

The Scientific World Journal
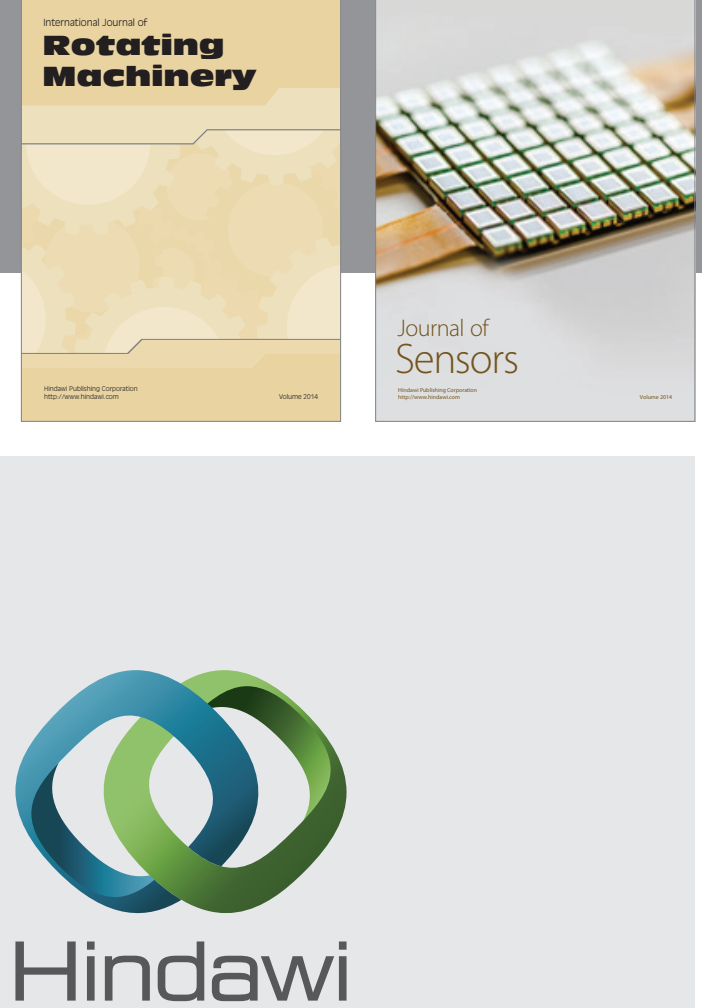

Submit your manuscripts at http://www.hindawi.com
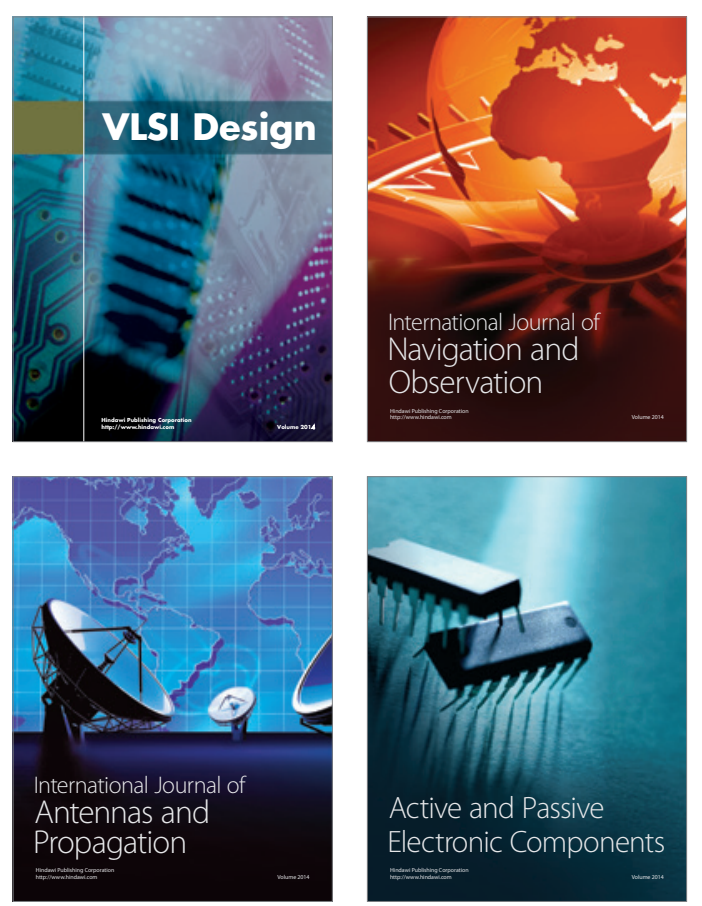
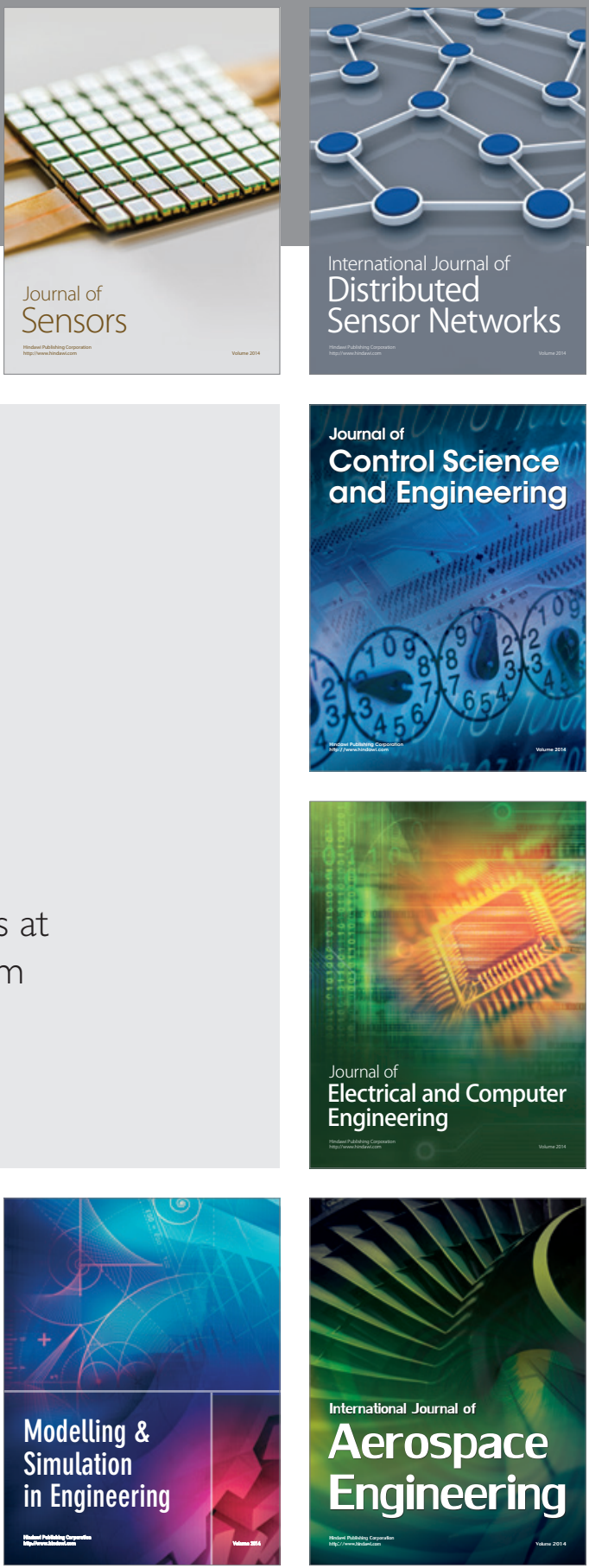

Journal of

Control Science

and Engineering
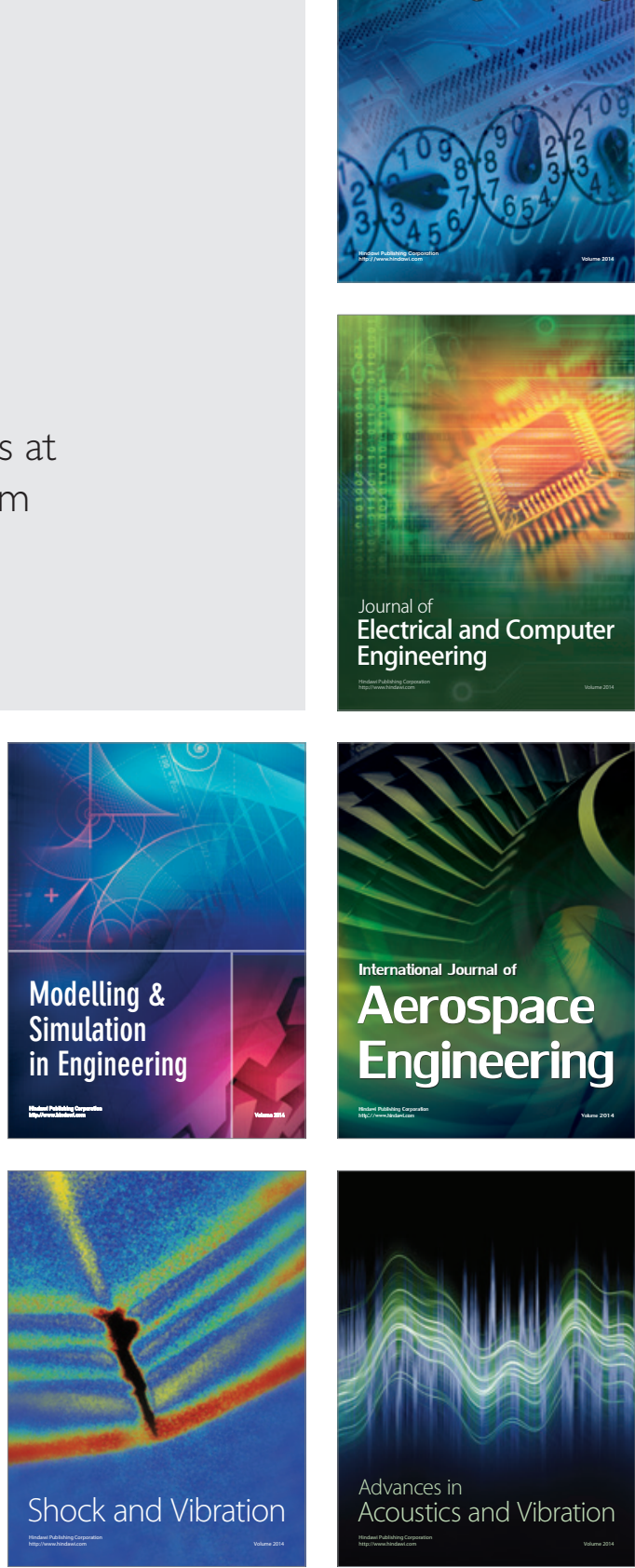